\title{
Stroke Prevention After Cryptogenic Stroke
}

\author{
Chinwe Ibeh ${ }^{1}$ (D) Mitchell S. V. Elkind ${ }^{1,2}$
}

Accepted: 26 August 2021 / Published online: 16 October 2021

This is a U.S. government work and not under copyright protection in the U.S.; foreign copyright protection may apply 2021

\begin{abstract}
Purpose of Review Cryptogenic stroke represents a heterogenous but clinically important collection of stroke etiologies for which our understanding continues to grow. Here, we review our current knowledge and most recent recommendations on secondary prevention for common causes of cryptogenic stroke including paroxysmal atrial fibrillation, atrial cardiopathy, patent foramen ovale, and substenotic atherosclerotic disease as well as the under-recognized mechanisms of occult malignancy, heart failure, and, most recently, infection with severe acute respiratory syndrome coronavirus-2 (SARS-CoV-2).

Recent Findings The results from recent observational studies and randomized clinical trials have provided greater insight into the causal relationship and attributable risk of these suspected etiologies and have identified potential strategies to reduce the rates of recurrence. However, further clinical trials are needed to confirm the benefits of specific stroke prevention strategies, including the patient populations most likely to benefit from anticoagulation.

Summary There is ongoing research aimed at both reducing the proportion of ischemic strokes classified as cryptogenic and resolving much of the clinical equipoise that still exists. The results of these studies have the potential to provide us with a better understanding of these occult mechanisms and allow for more targeted interventions.
\end{abstract}

Keywords Cryptogenic stroke $\cdot$ Atrial fibrillation $\cdot$ Heart failure $\cdot$ Atrial cardiopathy $\cdot$ Malignancy, COVID-19

Abbreviations
AAN
AF
AHA
ASCO

ASSERT

CCS
American Academy of Neurology

Atrial fibrillation

American Heart Association

Atherosclerosis, Small vessel dis-

ease, Cardiac source, Other cause

Atrial Fibrillation Reduction Atrial

Pacing Trial

Causative Classification of Stroke

System
CLOSE

CLOSURE

COMMANDER-HF

This article is part of the Topical Collection on Stroke

Chinwe Ibeh

ci73@cumc.columbia.edu

Mitchell S. V. Elkind

mse13@cumc.columbia.edu

1 Department of Neurology, Vagelos College of Physicians and Surgeons, Columbia University and New YorkPresbyterian Hospital, 710 W 168th St, New York, NY, USA

2 Department of Epidemiology, Mailman School of Public Health, Columbia University, New York, NY, USA
Closure of Patent Foramen Ovale or Anticoagulants Versus Antiplatelet Therapy to Prevent Stroke Recurrence

A Prospective, Multicenter, Randomized Controlled Trial to Evaluate the Safety and Efficacy of the Starflex ${ }^{\circledR}$ Septal Closure System Versus Best Medical Therapy in Patients with a Stroke And/Or Transient Ischemic Attack Due to Presumed Paradoxical Embolism Through a Patent Foramen Ovale Randomized, Double-blind, Event-driven, Multicenter Study Comparing the Efficacy and Safety of Rivaroxaban With Placebo for Reducing the Risk of Death, Myocardial Infarction or Stroke in Subjects With Heart Failure and Significant Coronary Artery Disease Following an Episode of Decompensated Heart Failure Computed tomography 


\begin{tabular}{|c|c|}
\hline DEFENSE-PFO & $\begin{array}{l}\text { Device Closure Versus Medical } \\
\text { Therapy for Cryptogenic Stroke } \\
\text { Patients With High-Risk Patent } \\
\text { Foramen Ovale Trial }\end{array}$ \\
\hline ESC & European Society of Cardiology \\
\hline ESUS & $\begin{array}{l}\text { Embolic stroke of undetermined } \\
\text { source }\end{array}$ \\
\hline FDG-PET & $\begin{array}{l}\text { Fluorodeoxyglucose-positron emis- } \\
\text { sion tomography }\end{array}$ \\
\hline MRI & Magnetic resonance imaging \\
\hline NASCET & $\begin{array}{l}\text { North American Symptomatic } \\
\text { Carotid Endarterectomy Trial }\end{array}$ \\
\hline NAVIGATE ESUS & $\begin{array}{l}\text { New Approach Rivaroxaban Inhibi- } \\
\text { tion of Factor Xa in a Global Trial } \\
\text { versus ASA to Prevent Embolism } \\
\text { in Embolic Stroke of Undetermined } \\
\text { Source }\end{array}$ \\
\hline PC & $\begin{array}{l}\text { Randomized clinical trial compar- } \\
\text { ing the efficacy of percutaneous } \\
\text { closure of patent foramen ovale } \\
\text { (PFO) with medical treatment in } \\
\text { patients with cryptogenic embolism }\end{array}$ \\
\hline PFO & Patent formen ovale \\
\hline REDUCE & $\begin{array}{l}\text { GORE® HELEX® Septal } \\
\text { Occluder/GORE® CARDIOFORM } \\
\text { Septal Occluder and Antiplate- } \\
\text { let Medical Management for } \\
\text { Reduction of Recurrent Stroke or } \\
\text { Imaging-Confirmed TIA in Patients } \\
\text { With Patent Foramen Ovale (PFO) }\end{array}$ \\
\hline RESPECT & $\begin{array}{l}\text { Randomized Evaluation of Recur- } \\
\text { rent Stroke Comparing PFO } \\
\text { Closure to Established Current } \\
\text { Standard of Care Treatment Trial }\end{array}$ \\
\hline RE-SPECT ESUS & $\begin{array}{l}\text { Dabigatran Etexilate for Secondary } \\
\text { Stroke Prevention in Patients With } \\
\text { Embolic Stroke of Undetermined } \\
\text { Source Trial }\end{array}$ \\
\hline TIA & Transient ischemic attack \\
\hline TOAST & $\begin{array}{l}\text { Trial of Org } 10,172 \text { in Acute Stroke } \\
\text { Treatment study }\end{array}$ \\
\hline WARCEF & $\begin{array}{l}\text { Warfarin Versus Aspirin in } \\
\text { Reduced Cardiac Ejection Fraction }\end{array}$ \\
\hline WASID & $\begin{array}{l}\text { Warfarin-aspirin symptomatic } \\
\text { intracranial disease }\end{array}$ \\
\hline
\end{tabular}

\section{Introduction}

Ischemic strokes can result from several different mechanisms, the majority of which can be readily identified following a standard diagnostic evaluation. However, in about $25 \%$ of cases stroke etiology remains unknown — a clinically important point as the effectiveness of secondary prevention strategies often hinges on accurate and timely identification of the underlying cause [1]. Our understanding of cryptogenic stroke has evolved through the years and depends on the classification system used. An early and commonly used system arose from the TOAST (Trial of Org 10,172 in Acute Stroke Treatment) study which classified ischemic strokes based on five potential etiologies: [1] large artery atherosclerosis, [2] cardioembolism, [3] small vessel occlusion, [4] other determined etiology (e.g., dissection), or [5] of undetermined source (i.e., cryptogenic) [2]. According to the TOAST system, strokes could be classified as cryptogenic [1] after an extensive evaluation, [2] after an incomplete evaluation, or [3] due to the presence of multiple competing etiologies. The simplicity of the system has made it widely popular for use in both clinical practice and scientific research. However, through the years, as stroke research has evolved (along with our standards for optimal care), TOAST's broad inclusion criteria for cryptogenic stroke has complicated efforts towards targeted medical management. Since then additional classification systems have been developed, emphasizing underlying mechanisms (causative) and/ or disease manifestations (phenotypic) (Table 1) [2-4]. In an attempt to identify a single and therapeutically distinct subset of patients with cryptogenic stroke, Hart and colleagues proposed the concept of ESUS, or embolic stroke of undetermined source, broadly defined as nonlacunar brain infarcts occurring in the absence of $[1] \geq 50 \%$ luminal atherosclerotic stenosis of the supplying extracranial or intracranial arteries, [2] any major-risk cardioembolic source, and [3] any other specific cause of stroke (e.g., dissection, vasospasm, drug abuse) [5]. With this distinction, the authors proposed there was likely a subset of cryptogenic strokes that were more likely embolic in origin and perhaps more likely to respond to anticoagulant therapy. However, even with these new constructs, cryptogenic stroke remains a diagnostic challenge. As the 10-year risk of recurrence is estimated to be as high as $30 \%$, investigations into potential sources of cryptogenic stroke should be focused and deliberate - guided by patient factors and clinical features aimed at increasing the yield of diagnostic studies and identifying patients who would likely benefit from targeted therapies [6].

In the last 5 years, several clinical trials have investigated the efficacy of newer therapies for specific conditions often implicated in cryptogenic stroke. Non-vitamin $\mathrm{K}$ oral antagonists (NOACs), such as dabigatran, rivaroxaban, and apixaban have been explored in patients with ESUS, heart failure, and malignancy with varying degrees of success [7, $8 \bullet \bullet, 9 \bullet]$. The results of these studies have inspired additional trials using these new agents in more select sub-populations. In addition, the recent CLOSE, REDUCE, and DEFENSEPFO studies identified patients with cryptogenic stroke and PFO who may benefit most from PFO closure, prompting a recent update in the recommendations from the American 
Academy of Neurology [10-12]. Although these discoveries highlight recent progress in the area of cryptogenic stroke, their gaps and limitations emphasize the need for continued work into interventions that may further reduce the risk of recurrence in these special populations.

\section{Paroxysmal Atrial Fibrillation}

Atrial fibrillation (AF) is a common cause of stroke, contributing to stasis and thrombus formation in the left atrium and appendage. In the diagnostic evaluation of the stroke patient, early electrocardiography (ECG) and at least $24 \mathrm{~h}$ of continuous telemetry to screen for AF are standard recommendations [13]. However, as patients with paroxysmal AF can remain in sinus rhythm throughout the length of their hospitalization, there is potential for a portion of these strokes to be misclassified as cryptogenic. Therefore, for patients with non-lacunar strokes and unrevealing preliminary assessments (e.g., no large artery stenosis or major cardioembolic source identified) prolonged cardiac monitoring is frequently utilized to evaluate for occult arrhythmias. Early observational studies showed that rates of detection for paroxysmal AF following cryptogenic stroke were directly related to duration of monitoring, ranging from 3 to $7 \%$ on shorter-term ECG and telemetry, to up to $30 \%$ after 3 years of monitoring with implantable loop recorders-trends later confirmed in two randomized trials [14-17]. Subsequent studies identified factors associated with increased likelihood of detection including older age, cortical appearance of stroke on cerebral imaging, and higher $\mathrm{CHA}_{2} \mathrm{DS}_{2}$-VASc score, as well as markers of left atrial disease including elevated $\mathrm{N}$-terminal pro-brain natriuretic peptide (NT-pro-BNP), $\mathrm{P}$ wave dispersion on ECG, and left atrial dilation [18, 19, 20•, 21].

However, a key question that often arises in the evaluation of cryptogenic stroke is exactly how much atrial fibrillation is necessary to be considered a risk factor for ischemic events. Although several studies have shown that the rate of detection increases with the duration of cardiac monitoring, the optimal duration of monitoring remains uncertain, as does the duration of dysrhythmia necessary to significantly increase the risk of stroke, warranting anticoagulation. In addition, although previous studies have associated paroxysmal AF with increased risk of ischemic stroke, direct causality has not consistently been established. In the prospective ASSERT study, over 2500 individuals without history of AF underwent cardiac pacemaker or defibrillator placement and were monitored for a mean of 2.5 years. Eventual detection of subclinical AF was predictive of ischemic stroke or systemic embolism (adjusted hazard ratio (aHR) 2.5; 95\% confidence interval (CI): 1.28-4.89)) [22••]. However, among those who developed ischemic stroke or embolization, $51 \%$ $(n=26)$ had subclinical AF $>6$ min detected at some point during monitoring but only 4 patients had an episode within 30 days prior to stroke [15]. Although questions remain regarding the utility of prolonged cardiac monitoring and the causal relationship between stroke and paroxysmal AF, currently the American Heart Association, the American Academy of Neurology and the European Society of Cardiology recommend short-term cardiac monitoring (e.g., 24-72 h) in the evaluation of cryptogenic stroke followed by longterm outpatient monitoring with either non-invasive ECG or insertable cardiac monitors for select patients [23, 24].

Table 1 Summary of ischemic stroke classification systems

\begin{tabular}{|c|c|c|c|}
\hline & TOAST [2] & CCS [4] & ASCO [3] \\
\hline Year published & 1993 & 2007 & 2009 \\
\hline Classification type & Causative & Causative and phenotypic & Phenotypic \\
\hline Subgroups & $\begin{array}{l}\text { 1) Large artery atherosclerosis } \\
\text { 2) Cardioembolic } \\
\text { 3) Small vessel occlusion } \\
\text { 4) Other determined } \\
\text { 5) Undetermined }\end{array}$ & $\begin{array}{l}\text { 1) Large artery atherosclerosis } \\
\text { 2) Cardio-aortic embolism } \\
\text { 3) Small artery occlusion } \\
\text { 4) Other determined } \\
\text { 5) Undetermined causes }\end{array}$ & $\begin{array}{l}\text { 1) Atherothrombosis } \\
\text { 2) Small vessel occlusion } \\
\text { 3) Cardiac pathology } \\
\text { 4) Other determined }\end{array}$ \\
\hline $\begin{array}{l}\text { Sub-categories for } \\
\text { undetermined } \\
\text { cause }\end{array}$ & $\begin{array}{l}\text { - Two or more causes identified } \\
\text { - Negative evaluation } \\
\text { - Incomplete evaluation }\end{array}$ & $\begin{array}{l}\text { - Cryptogenic embolism } \\
\text { - Other cryptogenic } \\
\text { - Incomplete evaluation } \\
\text { - Unclassified }\end{array}$ & $\bullet N / A$ \\
\hline Required diagnostics & - Not specified & $\begin{array}{l}\text { - Brain CT/MRI } \\
\text { - ECG } \\
\text { - Echocardiogram } \\
\text { - Extra- and intracranial vessel imaging }\end{array}$ & $\begin{array}{l}\text { - Incorporates completeness of the diagnostic } \\
\text { evaluation into subtype assignment }\end{array}$ \\
\hline Comments & $\begin{array}{l}\text { - Simple } \\
\text { - Widely used in clinical prac- } \\
\text { tice and medical literature }\end{array}$ & $\begin{array}{l}\text { - Web-based application } \\
\text { - Uses evidence-based criteria } \\
\text { - Validated in multiple studies }\end{array}$ & $\begin{array}{l}\text { - Assigns a level of likelihood to all potential } \\
\text { causes } \\
\text { - Describes multiple phenotypes }\end{array}$ \\
\hline
\end{tabular}

ASCO atherosclerosis, small vessel disease, cardiac source, other cause, CCS Causative Classification of Stroke System, CT computed tomography, ECG electrocardiogram, MRI magnetic resonance imaging, TOAST Trial of Org 10,172 in Acute Stroke Treatment study 


\section{Atrial Cardiopathy}

To implicate occult atrial fibrillation as a mechanism behind regional stasis and clot formation in patients with cryptogenic stroke would presumably require that these episodes occur prior to any ischemic event and within a reasonable proximity of time. However, as observed in the ASSERT study, episodes occurring long after an ischemic stroke have also been associated with increased risk [15]. This lack of a temporal relationship between the onset of arrhythmia and incident stroke has given rise to an alternative theory-that these dysrhythmias, instead of being causal, are simply markers of more global atrial pathology. Several biomarkers of atrial disease (or atrial cardiopathy) have been identified and there is increasing focus on the relationship between these markers and the risk of stroke and stroke recurrence. In a subset analysis of the large, prospective Atherosclerosis Risk in Communities (ARIC) study, prolonged terminal force in V1 on ECG (a common marker of atrial abnormality) was associated with incident non-lacunar ischemic stroke (HR, 1.49; 95\% CI: 1.07-2.07) versus lacunar (HR, 0.89 ; 95\% CI: 0.57-1.40), even after adjustment for vascular confounders and incident AF [25]. In another populationbased analysis, plasma troponin $\mathrm{T}$ (TnT) and NT-pro-BNP (a marker of atrial stretch and volume overload) were both positively associated with non-lacunar stroke (particularly cardioembolic subtypes), as opposed to lacunar, after adjusting for vascular risk factors and cardiac disease [26]. And in an imaging analysis of the large, multi-ethnic Northern Manhattan Study, the presence of left atrial enlargement almost tripled the risk of recurrent cryptogenic or cardioembolic stroke even after adjustment for $\mathrm{AF}$ and incident heart failure (aHR 2.83, 95\% CI: 1.03-7.81) [27].

Considering the effectiveness of anticoagulation in reducing the risk of recurrent stroke in AF, some have hypothesized that atrial cardiopathy might respond in a similar fashion. ESUS was conceptualized to identify a subset of patients with the highest likelihood of having a more proximal source of stroke, and thus more likely to benefit from anticoagulation. Two important clinical trials recently explored this hypothesis. The New Approach Rivaroxaban Inhibition of Factor Xa in a Global Trial versus ASA to Prevent Embolism in Embolic Stroke of Undetermined Source (NAVIGATE ESUS) trial compared the oral anticoagulant rivaroxaban to aspirin therapy in patients diagnosed with embolic stroke of undetermined source [8••]. A total of 7213 participants had been followed for a median of 11 months when the trial was terminated early for medical futility. No difference was seen in the rate of the primary efficacy outcome of first recurrent stroke or systemic embolism between the rivaroxaban and aspirin groups (annualized rate of 5.1\% versus $4.8 \%$; HR, 1.07 ; 95\% CI: 0.87-1.33) though major bleeding occurred more frequently in the rivaroxaban group (annualized rate 1.8\% versus $0.7 \%$; HR, 2.72; 95\% CI: 1.68-4.39). The following year the Dabigatran Etexilate for Secondary Stroke Prevention in Patients With Embolic Stroke of Undetermined Source (RE-SPECT ESUS) Trial reported results comparing dabigatran to aspirin in patients with ESUS [7]. After following 5390 participants a median of 19 months, the rate of recurrent stroke (ischemic, hemorrhagic, or unspecified) did not differ between the dabigatran and aspirin groups (4.1\%/year versus $7.7 \%$ year; HR, 0.85 ; 95\% CI: 0.69-1.03) while major bleeding occurred in $2.9 \%$ in the dabigatran group and $2.4 \%$ in the aspirin group (HR, 1.19; 95\% CI: 0.85-1.66). Although these two clinical trials failed to demonstrate the efficacy of NOACs in patients with ESUS, in a secondary analysis of patients identified as having both ESUS and markers of atrial cardiopathy, the oral anticoagulant rivaroxaban was shown to significantly reduce the risk of ischemic stroke $(1.7 \%$ per year) when compared to aspirin therapy (6.5\% per year) (HR: 0.26 ; 95\% CI: 0.07-0.94) [7, 8••, 28]. The AtRial Cardiopathy and Antithrombotic Drugs In Prevention After Cryptogenic Stroke (ARCADIA) trial and the Apixaban for Treatment of Embolic Stroke of Undetermined Source (ATTICUS) study are two ongoing clinical trials investigating the utility of apixaban in patients with ESUS and atrial cardiopathy (NCT03192215, NCT02427126). The results of these studies may provide evidence for more selective use of these novel agents in this high-risk population.

\section{Patent Foramen Ovale}

Paradoxical embolization through cardiac septal defects, particularly a patent foramen ovale (PFO), is another potential mechanism of stroke. However, as these defects are highly prevalent in the general population (occurring in as many as $25 \%$ ) the degree to which an ischemic stroke can be attributed to a PFO in the individual patient can be difficult to ascertain [29]. PFOs have a reported prevalence of $50 \%$ in patients with cryptogenic stroke and are often accompanied by atrial septal aneurysms (ASA), redundant mobile interatrial tissue that periodically bulges into the right and left atria during the cardiac cycle [30]. While ASA occurs in only $2.2 \%$ of the general population it can be seen in over $30 \%$ of patients with PFO who develop cryptogenic stroke [31].

In an attempt to stratify patients with PFO by the degree to which their defects are likely causal, as well as stratify by their risk of stroke recurrence, Kent and colleagues developed the Risk of Paradoxical Embolism (RoPE) score, a 10-point scoring system attributing points for factors such as younger age, cortical topography of infarct, and absence of traditional stroke risk factors [32]. Higher scores (associated 
with younger patients with embolic appearing strokes and minimal stroke risk factors) correlate with a greater likelihood of a PFO being causal and a lower risk of stroke recurrence. Patients with lower scores (e.g., older patients and those with multiple vascular risk factors) are more likely to have had a stroke unrelated to their PFO and have an overall higher risk of stroke recurrence. In addition, structural features of the PFO itself have also been used for risk stratification. The size of the defect (inferred from the degree of right-to-left shunt) as well as the presence of ASA and its degree of excursion have all been associated with greater odds of ischemic stroke [31].

Transcranial doppler ultrasonography with agitated saline is the most sensitive modality for the detection of PFO and should be performed in patients for whom PFO is strongly suspected but not seen on initial transthoracic echocardiogram (TTE) $[33,34 \bullet]$. This can be followed by transesophageal echocardiogram (TEE) to evaluate the size of the defect, degree of shunt, and presence of any associated ASA-assessments which are necessary in the evaluation for possible closure. In addition, if a PFO is identified and determined to likely be causal, ultrasound phlebography is generally recommended to evaluate for deep venous thrombosis (DVT), as the prevalence of DVTs in these patients has been reported to be as high as $22 \%[35,36]$.

Treatment options for patients with cryptogenic stroke in the setting of PFO include medical management with either antiplatelet therapy or anticoagulation and consideration for PFO closure. The utility of and recommendations for device closure have evolved over the years in parallel with multiple clinical trials comparing percutaneous closure to best medical therapy (see Table 2) [10-12, 37-39]. The results of the recent CLOSE, REDUCE, and DEFENSE-PFO studies in particular identified a subset of patients with cryptogenic stroke and PFO who may benefit most from PFO closure for secondary prevention [10-12]. And in a recent metaanalysis of four previous PFO closure trials, device closure was associated with a significantly lower rate of recurrent stroke compared to medical therapy $1.2 \%$ vs $4.1 \%$ (RD, 0.031; CI: 0.051 to $0.010 ; I^{2}=61 \%$ ) [40]. Accordingly, the most recent guidelines from the AAN recommend consideration of PFO closure (in addition to antiplatelet therapy) for patients $\leq 60$ years with embolic-appearing strokes if a thorough diagnostic evaluation is otherwise unrevealing $[41 \bullet \bullet]$.

\section{Heart Failure}

Heart failure affects approximately 6 million Americans and the prevalence is expected to increase markedly as the population ages [42]. Previous reports have estimated heart failure to be present in $10-24 \%$ of patients with stroke but is only attributed as the cause in $9 \%[43,44]$. This is likely due to the fact heart failure is often accompanied by more traditional stroke risk factors such as atrial fibrillation, diabetes, hypertension, coronary artery disease and obesity. Atrial fibrillation in particular frequently co-occurs with heart failure and, when present together, has been associated with a fivefold increase in risk of stroke compared to the general population [45]. The presence of AF represents a clear indication for anticoagulation therapy following ischemic stroke [13]. However, there is limited evidence regarding the risk of stroke in patients with heart failure and sinus rhythm and whether these patients too may benefit from anticoagulation for stroke risk reduction.

Regional stasis, endothelial dysfunction, hypercoagulability, and impaired forward flow have all been associated with left ventricular dysfunction and predispose patients with heart failure to the development of intracardiac thrombi and systemic embolization, even in the absence of AF [46]. There is, thus, rationale for the use of anticoagulants. In one of the earliest studies exploring this, over 1500 patients with $\mathrm{LVEF} \leq 35 \%$ and sinus rhythm were randomly assigned to warfarin, aspirin, or clopidogrel for primary prevention [47]. Though the study was terminated early due to difficulties with enrollment, warfarin was found to reduce the incidence of nonfatal stroke compared to antiplatelets but was accompanied by an increased incidence of major hemorrhage. Similarly, in the larger Warfarin versus Aspirin Treatment in the Reduced Cardiac Ejection Fraction (WARCEF) study, over 2300 patients with sinus rhythm and LVEF $\leq 35 \%$ were randomized to either warfarin or aspirin therapy for primary prevention [48]. Warfarin was associated with a significant reduction in the risk of ischemic stroke (HR: 0.52; 95\% CI: 0.33-0.82). However, these benefits were once again off-set by significantly higher rates of major hemorrhage (HR: 1.65 ; 95\% CI: 1.34-2.05). Nevertheless, with the advent of NOACs and their comparably lower risk of major bleeding, the potential benefit of anticoagulant therapy in the heart failure population was re-explored in the recent COMMANDER-HF study. Here, investigators compared the safety and efficacy of low dose rivaroxaban vs placebo added to a background of antiplatelet therapy in patients with chronic ischemic heart failure $(\mathrm{EF} \leq 40 \%)$ recently treated for acute decompensation. After a median followup of 21.1 months, the investigators found no difference in either the primary outcome (of death, myocardial infarction, or stroke) or the principal safety outcome between the two groups [49•]. However, in a separate post hoc analysis, the addition of rivoraxaban was shown to reduce the risk of ischemic stroke by $36 \%$ ( 0.86 events vs. 1.34 events per 100 patient-years; HR: 0.64; 95\% CI: 0.43-0.95) and the principal safety endpoint of major bleeding occurred at similar rates in the two groups [50•]. Though encouraging, prospective randomized clinical trials are necessary to confirm these 


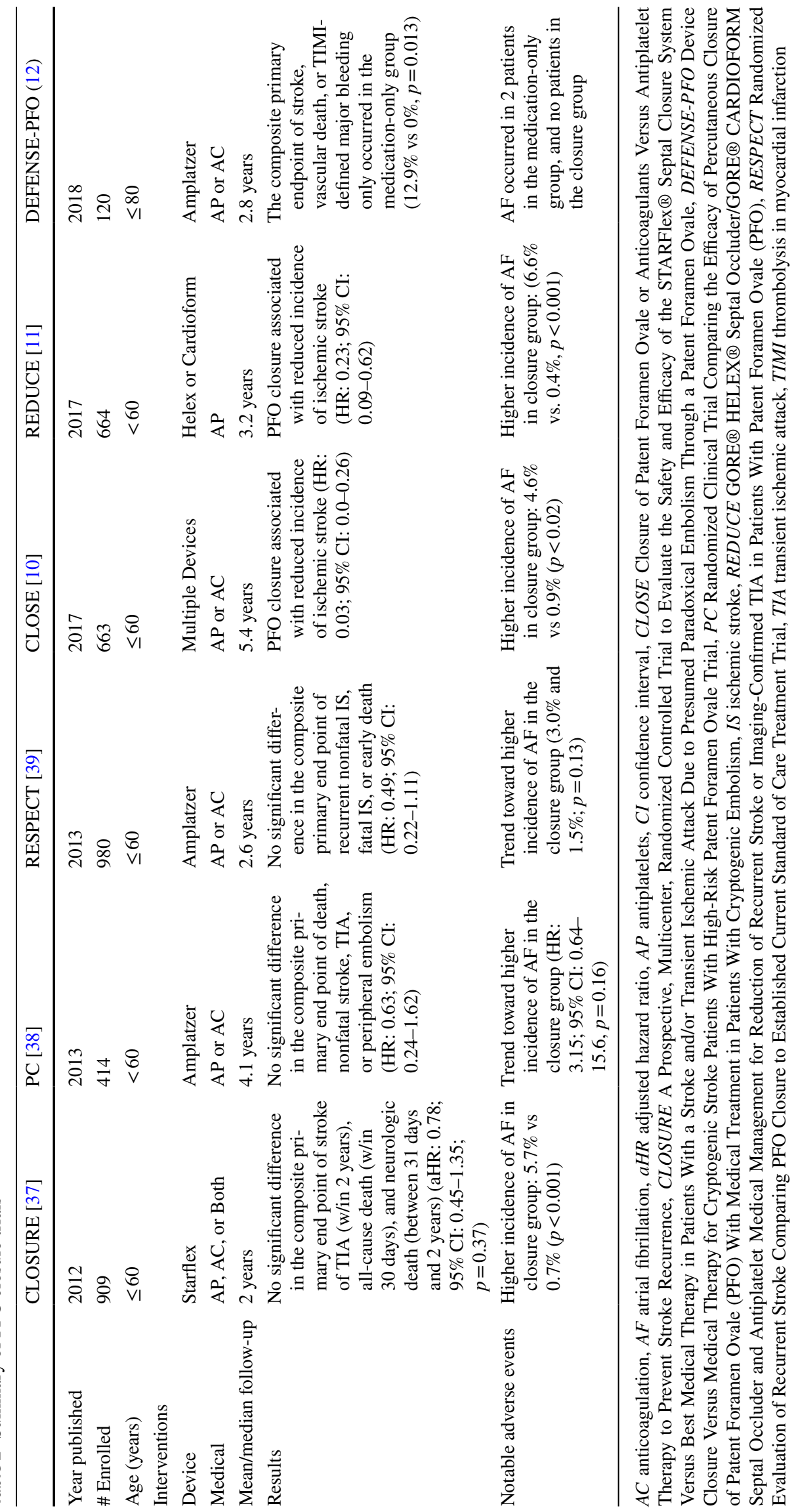


results and identify the subset of patients with isolated heart failure who may benefit most from anticoagulation for stroke risk reduction.

\section{Substenotic Atherosclerosis}

The relevance of substenotic large artery atherosclerotic lesions in the evaluation for potential causes of stroke is uncertain as the term "clinically significant" is generally reserved for lesions causing 50\% stenosis or more. However, there is increasing appreciation of the risk of stroke associated with "high risk" or "unstable" plaques, irrespective of their associated degree of luminal narrowing. Along the carotids, evidence of ulceration, friability, intraplaque hemorrhage or superimposed thrombus are all suggestive of lesions with the potential for thromboembolism and distal occlusion [51]. In one imaging analysis using high-resolution MRA in a cohort of patients with cryptogenic stroke, $25 \%$ of patients had evidence of intraplaque hemorrhage within substenotic carotid lesions ipsilateral to their stroke, while no lesions were found on the contralateral side [52]. Similarly, in a smaller study combining the modalities of MRI with FDG-PET, complex carotid plaques identified on MRI showed increased tracer uptake on PET and were more commonly found ipsilateral to regions of ischemic stroke [53].

Determining which atherosclerotic plaques are prone to rupture is an important emerging area of stroke research. Newer high-resolution, multi-contrast MRI techniques have been able to identify and characterize plaque components predictive of subsequent stroke (including intraplaque hemorrhage, lipid-rich necrotic cores, and thin/ruptured fibrous caps) with high fidelity [54•]. In addition, ongoing studies are evaluating the role of high-resolution MRI in the monitoring of disease progression and response to therapy [54•, 55]. However, as the WASID trial showed no benefit with the use of warfarin over aspirin for symptomatic intracranial disease and NASCET limited the benefits of endarterectomy to patients with $\geq 50 \%$ stenosis extracranially, antiplatelet therapy, high-dose statin, and risk factor modification remain standard of care for these lesions [13, 56, 57].

\section{Aortic Atheroma}

Aortic plaques that are thick ( $\geq 4 \mathrm{~mm}$ ), protruding, or feature mobile components have been associated with stroke and increased risk of vascular events [58]. These complex lesions can either have intrinsic atheromatous deposits (which can rupture and embolize) or feature irregular surfaces where extrinsic thrombi can accumulate and eventually embolize as well. In one study plaques $\geq 4 \mathrm{~mm}$ were associated with a ninefold increase in odds of ischemic stroke (95\% CI: 3.3-25.2) even after adjustment for atherosclerotic risk factors [59]. And in one autopsy study of patients with ischemic stroke, ulcerated aortic arch plaques were seen in $61 \%$ of patients with cryptogenic stroke versus only $22 \%$ of patients with known etiologies [60].

In one early, matched analysis examining the effects of statins, warfarin, and antiplatelet therapy in patients with severe aortic plaques, statins were found to be the only agent protective of subsequent embolic events (OR: 0.3; 95\% CI: 0.2-0.6; vs warfarin: OR: 0.7; 95\% CI: $0.4-1.2$ and aspirin: OR: $1.4 ; 95 \%$ CI: $0.8-2.4$ ) [61]. In another study specifically examining patients with a history of systemic embolism in the setting of mobile atheroma, warfarin was shown to be efficacious in reducing the risk of recurrent vascular events [62]. However in the randomized, open-label Aortic Arch Related Cerebral Hazard (ARCH) trial comparing dual antiplatelet therapy to warfarin in patients with plaques $\geq 4 \mathrm{~mm}$, dual antiplatelets were shown to non-significantly reduce the rates of vascular events compared to anticoagulation (HR: 0.76; 95\% CI: 0.36-1.61) [63]. But the results were inconclusive as the study was terminated early due to slow recruitment. Therefore, as with substenotic carotid disease, the mainstay of secondary prevention for patients with aortic atheromas continues to be aggressive management of systemic atherosclerosis (e.g., antiplatelet and lipid lowering therapy, blood pressure and glycemic control, and smoking cessation) [13].

\section{Occult Malignancy}

There are currently over 13 million people in the USA living with cancer, and stroke can complicate the course in up to $15 \%[64,65]$. Out of all the stroke subtypes, cryptogenic stroke has been reported to have the strongest association with malignancy (accounting for nearly half of all cancerrelated strokes) and is associated with increased severity, increased mortality, and increased rates of recurrence [66, 67]. There is currently no consensus as to when a malignancy evaluation is indicated in cryptogenic stroke or consensus on the extent of the evaluation. However, several studies have investigated clinical markers associated with cancer-related stroke that may help with risk stratification. In 2019, Nouh et al. described the radiographic "three territory sign," suggestive of occult malignancy in patients presenting with ischemic stroke [68•]. In their report, the presence of coincident DWI lesions in the bilateral hemispheres and posterior circulation had a specificity of $96.4 \%$ for occult cancer when compared to other stroke etiologies, including AF. Associations with serological markers including elevated D-dimer, CRP, fibrinogen, and ESR have also been described [69]. And in 2014, Guo and colleagues 
correlated the combination of multiple territory infarcts on imaging along with D-dimer levels $\geq 0.55 \mathrm{mg} / \mathrm{L}$ with a $99.7 \%$ specificity and $92.9 \%$ positive predictive value for cancer-related stroke [70]. Occult malignancy should therefore be considered in the evaluation for cryptogenic stroke in patients with evidence of infarcts in multiple vascular territories, abnormal inflammatory markers, and one or more high-risk patient-related factors (e.g., age $\geq 65$ years, unexplained weight loss, smoking or family history). Initial testing can begin with age-appropriate cancer screening as well as CT of the chest, abdomen, and pelvis. However, in patients with known malignancy, evaluation should include [1] upper and lower extremity ultrasound phlebography (if right-to-left shunt is present) to evaluate for possible DVT, as well as [2] transesophageal echocardiography (if TTE is unrevealing) to look for evidence of marantic endocarditis, as the presence of either of these findings would warrant anticoagulation therapy.

If anticoagulation is indicated, low molecular weight heparin (LMWH) had been the preferred first-line treatment for cancer-related VTE given reports of improved efficacy and safety profile compared to warfarin therapy [71]. However, in recent years, direct oral anticoagulants have been given considerable attention for their comparable efficacy and ease-of-use. Early investigations supported the use of agents like rivaroxaban and edoxaban for cancer-related thrombosis but have been limited by concerns of major bleeding [72]. However, a recent multi-national randomized trial comparing apixaban to the LMWH, dalteparin, showed noninferiority of the NOAC without increased risk of major bleeding. Apixaban thus may be considered as an alternative to LMWH for cancer-related thromboembolism [9•]. However, in the absence of a clear source of embolism, antiplatelet therapy remains standard of care for patients with malignancy and ischemic stroke.

\section{COVID-19}

In late 2019, a new strain of coronavirus causing a highly contagious, severe pneumonia was first reported in Wuhan, China. In the ensuing months the severe acute respiratory syndrome coronavirus-2 (SARS-CoV-2) spread across the world, setting off a global pandemic that as of March 1, 2021, infected more than 110 million people and claimed nearly 2.5 million lives [73]. Though respiratory illness has been the most common manifestation of coronavirus disease 2019 (COVID-19), increased rates of systemic thromboembolism have also been described, including stroke. According to one meta-analysis of 30 international studies, stroke had a reported frequency of $1.74 \%$ (95\% CI: $1.09-2.51 \%$ ) in patients hospitalized with COVID-19, compared to the $0.6 \%-0.8 \%$ quoted in the general population $[42,74 \bullet \bullet$. The relationship between stroke and infection, particularly upper respiratory illness, has been previously described [75-78]. However, in a recent report comparing rates of ischemic stroke in patients with SARS-CoV-2 to a historic cohort of patients with influenza, the odds of stroke were sevenfold greater in patients infected with COVID-19-an association that persisted after adjusting for vascular risk factors and severity of respiratory illness [79•].

Proposed mechanisms of ischemic stroke in patients with COVID-19 include secondary hypercoagulability, immunemediated endothelial injury, and systemic cytokine release [80]. Despite these theoretical mechanisms, a disproportionate number of these strokes are classified as cryptogenic (see Fig. 1). In another meta-analysis of 183 patients with COVID-related stroke, cryptogenic was the most common subtype, accounting for $50.7 \%$ of cases (twice the proportion of strokes in most population studies) [81]. This appears to have prognostic import. In a study comparing a cohort of patients presenting with stroke during the height of the 2020 pandemic to historic controls one year prior, the rate of cryptogenic stroke was significantly higher in patients infected with COVID-19 (42.6\% versus $19.6 \%, p<0.001)$ and was associated with higher rates of in-hospital mortality (38.1\% versus $7.8 \%, p<0.001$ ) [82]. In another report, patients with COVID-related stroke labeled as cryptogenic had a higher risk of hemorrhagic transformation (comparable to cardioembolic subtypes) and were possibly more likely to be discharged with greater disability $(p=0.07)$ despite similar premorbid functioning [83]. In addition, COVID-19 patients with cryptogenic stroke had a significantly higher risk of in-hospital mortality compared to other subtypes (OR 2.27; 95\% CI: 1.01-5.08). And COVID-related cryptogenic stroke remained independently associated with in-hospital mortality after adjusting for age, sex, and stroke severity (aOR 5.16, 95\% CI: 1.41-18.87).

Though the theory of an immune-mediated hypercoagulable state in patients with COVID-19 has garnered much attention as a possible mechanism for ischemic stroke (particularly strokes that are cryptogenic) the pathophysiological link between COVID and increased thrombogenesis is still under investigation [84]. The results of a recent multiplatform, randomized clinical trial suggest initial management with therapeutic unfractionated or low molecular weight heparin may improve in-hospital survival and reduce the need for cardiovascular and respiratory organ support in non-critically ill patients hospitalized with COVID-19 [85]. Two additional trials investigating the efficacy of therapeutic anticoagulation in patients with COVID-19 are ongoing (NCT04345848, NCT04406389) and the results of these studies may help determine optimal primary and secondary prevention strategies for this emerging subset of stroke patients. 


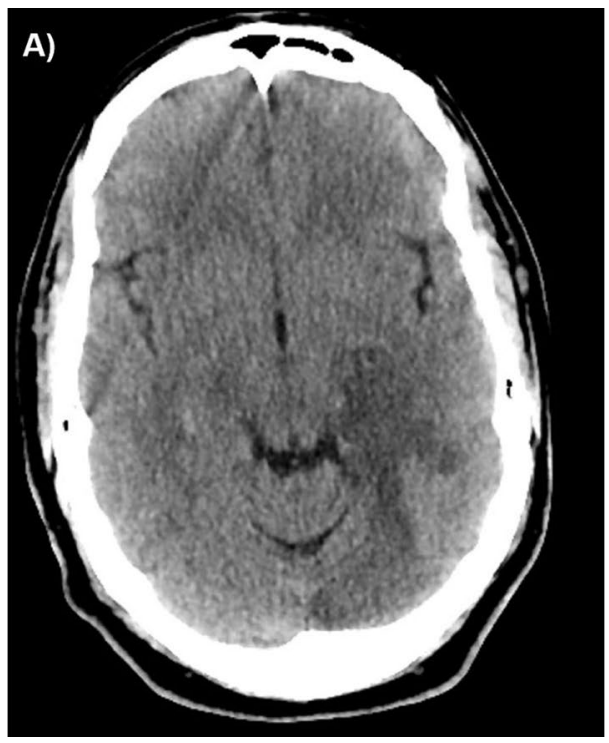

Fig. 1 CT head demonstrating left parieto-occipital hypodensity with localized sulcal effacement and edema (A) along with CTA showing partial occlusion of the distal left PCA (B, red arrow), consistent with embolic infarction and partial recanalization, in a 56-year-old man with poorly controlled diabetes and hypertension who presented with right hemianopsia and alexia without agraphia. He had a flu-like ill-

\section{Future Directions and Conclusion}

Though fundamentally nonspecific, cryptogenic stroke represents a clinically important stroke subtype that warrants a careful and tailored evaluation. The risk of recurrence for patients with cryptogenic stroke is not negligible and further research is necessary to better stratify these patients and reduce the rates of recurrent events. Accordingly, current research in the area of cryptogenic stroke is two-pronged, with efforts directed at both [1] reducing the proportion of ischemic strokes classified as undetermined and [2] resolving much of the clinical equipoise in medical management that still exists. Promising areas of research in stroke diagnostics include histopathologic clot analysis (correlating red cell and platelet composition to likely sources of embolization) and gene profiling with RNA expressed in blood cells at the time of stoke onset $[86 \bullet, 87,88]$. Both have the potential to serve as new biomarkers to help delineate stroke subtypes on the cellular and molecular levels, respectively. In addition, clinical trials evaluating the safety and efficacy of anticoagulation in select patients with ESUS, COVID-related stroke, and stroke in the setting of malignancy are all ongoing and the results may provide additional guidance on optimal management. Together these efforts and future investigations will hopefully provide us with a better understanding of these occult mechanisms and improve secondary prevention strategies.

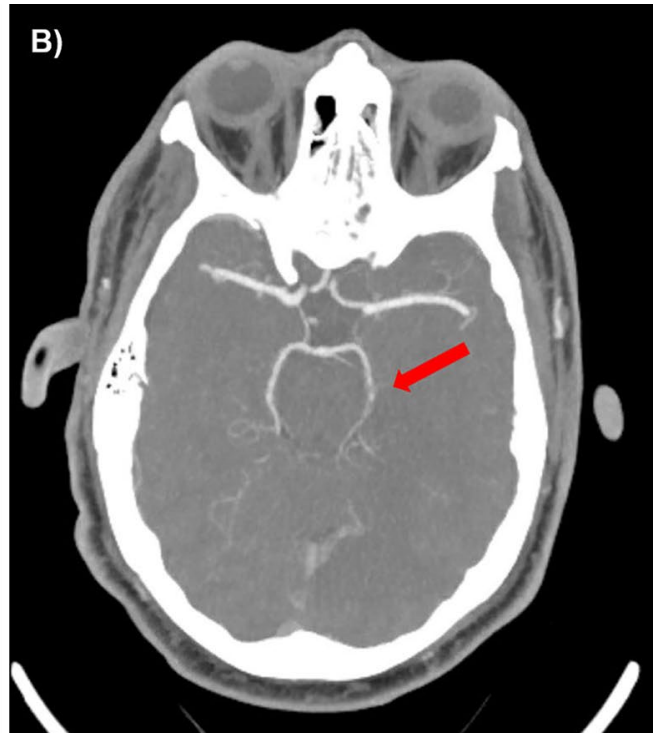

ness and was diagnosed with COVID-19 approximately three months before, followed by severe cardiomyopathy with left ventricular ejection fraction of $15 \%$, unexplained by coronary artery disease. There was severe left atrial enlargement but no atrial fibrillation. He was thought to have a viral cardiomyopathy due to SARS-CoV-2, complicated by heart failure and cardioembolic stroke

Funding This work was funded by the National Institutes of Health (NINDS T32 NS07153).

\section{Compliance with Ethical Standards}

Conflict of Interest Dr. Elkind declares receipt of research funding in kind from the BMS-Pfizer Alliance for Eliquis ${ }^{\circledR}$ and research funding, but no personal compensation, from Roche, both for a National Institutes of Health-funded trial of stroke prevention; and royalties from UpToDate for chapters on cryptogenic stroke and COVID-19. Dr. Ibeh declares no conflict of interest.

Human and Animal Rights and Informed Consent This article does not contain primary reporting of any studies with human or animal subjects performed by any of the authors.

\section{References}

Papers of particular interest, published recently, have been highlighted as:

- Of importance

$\bullet$ Of major importance

1. Ornello R, Degan D, Tiseo C, Di Carmine C, Perciballi L, Pistoia F, et al. Distribution and temporal trends from 1993 to 2015 of ischemic stroke subtypes: a systematic review and meta-analysis. Stroke. 2018;49(4):814-9.

2. Adams Jr HP, Bendixen BH, Kappelle LJ, Biller J, Love BB, Gordon DL, Marsh 3rd EE. Classification of subtype of acute ischemic stroke. Definitions for use in a multicenter clinical trial. 
TOAST. Trial of Org 10172 in Acute Stroke Treatment. stroke. 1993 Jan;24(1):35-41.

3. Amarenco P, Bogousslavsky J, Caplan LR, Donnan GA, Hennerici MG. New approach to stroke subtyping: the A-S-C-O (phenotypic) classification of stroke. Cerebrovasc Dis. 2009;27(5):502-8.

4. Ay H, Benner T, Arsava EM, Furie KL, Singhal AB, Jensen MB, et al. A computerized algorithm for etiologic classification of ischemic stroke: the Causative Classification of Stroke System. Stroke. 2007;38(11):2979-84.

5. Hart RG, Diener H-C, Coutts SB, Easton JD, Granger CB, O'Donnell $\mathrm{MJ}$, et al. Embolic strokes of undetermined source: the case for a new clinical construct. The Lancet Neurology. 2014;13(4):429-38.

6. Li L, Yiin GS, Geraghty OC, Schulz UG, Kuker W, Mehta Z, et al. Incidence, outcome, risk factors, and long-term prognosis of cryptogenic transient ischaemic attack and ischaemic stroke: a population-based study. Lancet Neurol. 2015;14(9):903-13.

7. Diener HC, Sacco RL, Easton JD, Granger CB, Bernstein RA, Uchiyama S, et al. Dabigatran for prevention of stroke after embolic stroke of undetermined source. N Engl J Med. 2019;380(20):1906-17.

8.• Hart RG, Sharma M, Mundl H, Kasner SE, Bangdiwala SI, Berkowitz SD, et al. Rivaroxaban for Stroke Prevention after Embolic Stroke of Undetermined Source. N Engl J Med. 2018;378(23):2191-201. The RESPECT ESUS trial did not show superiority of the oral anticoagulant rivaroxaban over aspirin therapy for secondary prevention following embolic stroke of undetermined source. The study however provided rationale for two clinical trials examining the efficacy of the oral non-vitamin $K$ antagonist apixaban for secondary prevention in patients with ESUS and evidence of atrial cardiopathy.

9.• Agnelli G, Becattini C, Meyer G, Munoz A, Huisman MV, Connors JM, et al. Apixaban for the Treatment of Venous Thromboembolism Associated with Cancer. N Engl J Med. 2020;382(17):1599-607. Clinical trial demonstrating noninferiority of the oral anticoagulant apixaban compared to subcutaneous dalteparin for the treatment of cancer-associated venous thromboembolism.

10. Mas JL, Derumeaux G, Guillon B, Massardier E, Hosseini H, Mechtouff L, et al. Patent foramen ovale closure or anticoagulation vs. antiplatelets after stroke. N Engl J Med. 2017;377(11):1011-21.

11. Sondergaard L, Kasner SE, Rhodes JF, Andersen G, Iversen HK, Nielsen-Kudsk JE, et al. Patent foramen ovale closure or antiplatelet therapy for cryptogenic stroke. N Engl J Med. 2017;377(11):1033-42.

12. Lee PH, Song JK, Kim JS, Heo R, Lee S, Kim DH, et al. Cryptogenic stroke and high-risk patent foramen ovale: the DEFENSEPFO Trial. J Am Coll Cardiol. 2018;71(20):2335-42.

13. Powers WJ, Rabinstein AA, Ackerson T, Adeoye OM, Bambakidis NC, Becker K, et al. Guidelines for the early management of patients with acute ischemic stroke: 2019 update to the 2018 guidelines for the early management of acute ischemic stroke: a guideline for healthcare professionals from the American Heart Association/American Stroke Association. Stroke. 2019;50(12):e344-418.

14. Sposato LA, Cipriano LE, Saposnik G, Ruiz Vargas E, Riccio PM, Hachinski V. Diagnosis of atrial fibrillation after stroke and transient ischaemic attack: a systematic review and metaanalysis. Lancet Neurol. 2015;14(4):377-87.

15. Brambatti M, Connolly SJ, Gold MR, Morillo CA, Capucci $\mathrm{A}$, Muto $\mathrm{C}$, et al. Temporal relationship between subclinical atrial fibrillation and embolic events. Circulation. 2014;129(21):2094-9.

16. Sanna T, Diener HC, Passman RS, Di Lazzaro V, Bernstein RA, Morillo CA, et al. Cryptogenic stroke and underlying atrial fibrillation. N Engl J Med. 2014;370(26):2478-86.
17. Gladstone DJ, Spring M, Dorian P, Panzov V, Thorpe KE, Hall $\mathrm{J}$, et al. Atrial fibrillation in patients with cryptogenic stroke. N Engl J Med. 2014;370(26):2467-77.

18. Favilla CG, Ingala E, Jara J, Fessler E, Cucchiara B, Messe SR, et al. Predictors of finding occult atrial fibrillation after cryptogenic stroke. Stroke. 2015;46(5):1210-5.

19. Suzuki S, Sagara K, Otsuka T, Kano H, Matsuno S, Takai H, et al. Usefulness of frequent supraventricular extrasystoles and a high CHADS2 score to predict first-time appearance of atrial fibrillation. Am J Cardiol. 2013;111(11):1602-7.

20. Diederichsen SZ, Haugan KJ, Brandes A, Graff C, Krieger D, Kronborg C, et al. Incidence and predictors of atrial fibrillation episodes as detected by implantable loop recorder in patients at risk: from the LOOP study. Am Heart J. 2020;219:117-27. This sub-study of the LOOP study provides evidence of biomarkers associated with incident atrial fibrillation among patients with implantable loop recorders.

21. Marks D, Ho R, Then R, Weinstock JL, Teklemariam E, Kakadia $\mathrm{B}$, et al. Real-world experience with implantable loop recorder monitoring to detect subclinical atrial fibrillation in patients with cryptogenic stroke: the value of $\mathrm{p}$ wave dispersion in predicting arrhythmia occurrence. Int J Cardiol. 2021;327:86-92.

22.• Healey JS, Connolly SJ, Gold MR, Israel CW, Van Gelder IC, Capucci A, et al. Subclinical atrial fibrillation and the risk of stroke. N Engl J Med. 2012;366(2):120-9. This secondary analysis of NAVIGATE ESUS provides evidence that the direct acting oral anticoagulant rivaroxaban reduces the risk of recurrent stroke in patients with embolic stroke of undetermined source with evidence of left atrial enlargement.

23. Culebras A, Messe SR, Chaturvedi S, Kase CS, Gronseth G. Summary of evidence-based guideline update: prevention of stroke in nonvalvular atrial fibrillation: report of the Guideline Development Subcommittee of the American Academy of Neurology. Neurology. 2014;82(8):716-24.

24. Hindricks G, Potpara T, Dagres N, Arbelo E, Bax JJ, BlomstromLundqvist C, et al. 2020 ESC Guidelines for the diagnosis and management of atrial fibrillation developed in collaboration with the European Association for Cardio-Thoracic Surgery (EACTS). Eur Heart J. 2021;42(5):373-498.

25. Kamel H, O'Neal WT, Okin PM, Loehr LR, Alonso A, Soliman EZ. Electrocardiographic left atrial abnormality and stroke subtype in the atherosclerosis risk in communities study. Ann Neurol. 2015;78(5):670-8.

26. Folsom AR, Nambi V, Bell EJ, Oluleye OW, Gottesman RF, Lutsey PL, et al. Troponin T, N-terminal pro-B-type natriuretic peptide, and incidence of stroke: the atherosclerosis risk in communities study. Stroke. 2013;44(4):961-7.

27. Yaghi S, Moon YP, Mora-McLaughlin C, Willey JZ, Cheung $\mathrm{K}$, Di Tullio MR, et al. Left atrial enlargement and stroke recurrence: the Northern Manhattan Stroke Study. Stroke. 2015;46(6):1488-93.

28. Healey JS, Gladstone DJ, Swaminathan B, Eckstein J, Mundl H, Epstein AE, et al. Recurrent Stroke With Rivaroxaban Compared With Aspirin According to Predictors of Atrial Fibrillation: Secondary Analysis of the NAVIGATE ESUS Randomized Clinical Trial. JAMA Neurol. 2019;76(7):764-73.

29. Homma S, Sacco RL. Patent foramen ovale and stroke. Circulation. 2005;112(7):1063-72.

30. Alsheikh-Ali AA, Thaler DE, Kent DM. Patent foramen ovale in cryptogenic stroke: incidental or pathogenic? Stroke. 2009;40(7):2349-55.

31. Cabanes L, Mas JL, Cohen A, Amarenco P, Cabanes PA, Oubary $\mathrm{P}$, et al. Atrial septal aneurysm and patent foramen ovale as risk factors for cryptogenic stroke in patients less than 55 years of age. A study using transesophageal echocardiography Stroke. 1993;24(12):1865-73. 
32. Kent DM, Ruthazer R, Weimar C, Mas JL, Serena J, Homma S, et al. An index to identify stroke-related vs incidental patent foramen ovale in cryptogenic stroke. Neurology. 2013;81(7):619-25.

33. Caputi L, Carriero MR, Falcone C, Parati E, Piotti P, Materazzo $\mathrm{C}$, et al. Transcranial Doppler and transesophageal echocardiography: comparison of both techniques and prospective clinical relevance of transcranial Doppler in patent foramen ovale detection. J Stroke Cerebrovasc Dis. 2009;18(5):343-8.

34. Yang X, Wang H, Wei Y, Zhai N, Liu B, Li X. diagnosis of patent foramen ovale: the combination of contrast transcranial doppler, contrast transthoracic echocardiography, and contrast transesophageal echocardiography. Biomed Res Int. 2020;2020:8701759. This study provides evidence for a practical approach to the evaluation of PFOs, combining the applications of contrast TCD, contrast TTE and contrast TEE.

35. Cramer SC, Rordorf G, Maki JH, Kramer LA, Grotta JC, Burgin WS, et al. Increased pelvic vein thrombi in cryptogenic stroke: results of the Paradoxical Emboli from Large Veins in Ischemic Stroke (PELVIS) study. Stroke. 2004;35(1):46-50.

36. Lethen H, Flachskampf FA, Schneider R, Sliwka U, Kohn G, Noth J, et al. Frequency of deep vein thrombosis in patients with patent foramen ovale and ischemic stroke or transient ischemic attack. Am J Cardiol. 1997;80(8):1066-9.

37. Furlan AJ, Reisman M, Massaro J, Mauri L, Adams H, Albers $\mathrm{GW}$, et al. Closure or medical therapy for cryptogenic stroke with patent foramen ovale. N Engl J Med. 2012;366(11):991-9.

38. Meier B, Kalesan B, Mattle HP, Khattab AA, Hildick-Smith D, Dudek D, et al. Percutaneous closure of patent foramen ovale in cryptogenic embolism. N Engl J Med. 2013;368(12):1083-91.

39. Carroll JD, Saver JL, Thaler DE, Smalling RW, Berry S, MacDonald LA, et al. Closure of patent foramen ovale versus medical therapy after cryptogenic stroke. N Engl J Med. 2013;368(12):1092-100.

40. De Rosa S, Sievert H, Sabatino J, Polimeni A, Sorrentino S, Indolfi C. Percutaneous closure versus medical treatment in stroke patients with patent foramen ovale: a systematic review and meta-analysis. Ann Intern Med. 2018;168(5):343-50.

41.•• Messe SR, Gronseth GS, Kent DM, Kizer JR, Homma S, Rosterman L, et al. Practice advisory update summary: patent foramen ovale and secondary stroke prevention: Report of the Guideline Subcommittee of the American Academy of Neurology. Neurology. 2020;94(20):876-85. This advisory update provides the most recent AAN recommendations on secondary prevention for patients with cryptogenic stroke and PFO.

42. Virani SS, Alonso A, Aparicio HJ, Benjamin EJ, Bittencourt MS, Callaway CW, et al. Heart disease and stroke statistics-2021 update: a report from the American Heart Association. Circulation. 2021;143(8):e254-743.

43. Haeusler KG, Laufs U, Endres M. Chronic heart failure and ischemic stroke. Stroke. 2011;42(10):2977-82.

44. Pullicino P, Homma S. Stroke in heart failure: atrial fibrillation revisited? J Stroke Cerebrovasc Dis. 2010;19(1):1-2.

45. Kang SH, Kim J, Park JJ, Oh IY, Yoon CH, Kim HJ, et al. Risk of stroke in congestive heart failure with and without atrial fibrillation. Int J Cardiol. 2017;248:182-7.

46. Lip GY, Ponikowski P, Andreotti F, Anker SD, Filippatos G, Homma S, et al. Thrombo-embolism and antithrombotic therapy for heart failure in sinus rhythm. A joint consensus document from the ESC Heart Failure Association and the ESC Working Group on Thrombosis. Eur J Heart Fail. 2012;14(7):681-95.

47. Massie BM, Collins JF, Ammon SE, Armstrong PW, Cleland JG, Ezekowitz M, et al. Randomized trial of warfarin, aspirin, and clopidogrel in patients with chronic heart failure: the Warfarin and Antiplatelet Therapy in Chronic Heart Failure (WATCH) trial. Circulation. 2009;119(12):1616-24.
48. Homma S, Thompson JL, Pullicino PM, Levin B, Freudenberger RS, Teerlink JR, et al. Warfarin and aspirin in patients with heart failure and sinus rhythm. N Engl J Med. 2012;366(20):1859-69.

49.• Zannad F, Anker SD, Byra WM, Cleland JGF, Fu M, Gheorghiade $\mathrm{M}$, et al. Rivaroxaban in patients with heart failure, sinus rhythm, and coronary disease. N Engl J Med. 2018;379(14):1332-42. COMMANDER-HF compared the addition of low dose rivaroxaban versus placebo to standard therapy in patients with chronic ischemic heart failure. The trial found no difference in either the primary outcome of death, myocardial infarction, or stroke or the primary safety outcome.

50. Mehra MR, Vaduganathan M, Fu M, Ferreira JP, Anker SD, Cleland JGF, et al. A comprehensive analysis of the effects of rivaroxaban on stroke or transient ischaemic attack in patients with heart failure, coronary artery disease, and sinus rhythm: the COMMANDER HF trial. Eur Heart J. 2019;40(44):3593602. This post hoc analysis of the COMMANDER-HF trial provides evidence that the addition of low-dose rivaroxaban to a background of standard medical therapy may help reduce the risk of stroke in patients with chronic ischemic heart failure without increased risk of major bleeding.

51. Takaya N, Yuan C, Chu B, Saam T, Underhill H, Cai J, et al. Association between carotid plaque characteristics and subsequent ischemic cerebrovascular events: a prospective assessment with MRI-initial results. Stroke. 2006;37(3):818-23.

52. Gupta A, Gialdini G, Lerario MP, Baradaran H, Giambrone A, Navi BB, et al. Magnetic resonance angiography detection of abnormal carotid artery plaque in patients with cryptogenic stroke. J Am Heart Assoc. 2015;4(6):e002012.

53. Hyafil F, Schindler A, Sepp D, Obenhuber T, Bayer-Karpinska A, Boeckh-Behrens T, et al. High-risk plaque features can be detected in non-stenotic carotid plaques of patients with ischaemic stroke classified as cryptogenic using combined (18)F-FDG PET/MR imaging. Eur J Nucl Med Mol Imaging. 2016;43(2):270-9.

54. Kassem M, Florea A, Mottaghy FM, van Oostenbrugge R, Kooi ME. Magnetic resonance imaging of carotid plaques: current status and clinical perspectives. Ann Transl Med. 2020;8(19):1266. Excellent review of advancements in carotid MRI imaging techniques and applications.

55. Brinjikji W, Lehman VT, Kallmes DF, Rabinstein AA, Lanzino $\mathrm{G}$, Murad MH, et al. The effects of statin therapy on carotid plaque composition and volume: a systematic review and metaanalysis. J Neuroradiol. 2017;44(4):234-40.

56. Chimowitz MI, Lynn MJ, Howlett-Smith H, Stern BJ, Hertzberg VS, Frankel MR, et al. Comparison of warfarin and aspirin for symptomatic intracranial arterial stenosis. N Engl J Med. 2005;352(13):1305-16.

57. Gaskie S. Carotid endarterectomy for symptomatic moderate stenosis. J Fam Pract. 1999;48(2):91-2.

58. Macleod MR, Amarenco P, Davis SM, Donnan GA. Atheroma of the aortic arch: an important and poorly recognised factor in the aetiology of stroke. Lancet Neurol. 2004;3(7):408-14.

59. Amarenco P, Cohen A, Tzourio C, Bertrand B, Hommel M, Besson $\mathrm{G}$, et al. Atherosclerotic disease of the aortic arch and the risk of ischemic stroke. N Engl J Med. 1994;331(22):1474-9.

60. Amarenco P, Duyckaerts C, Tzourio C, Henin D, Bousser MG, Hauw JJ. The prevalence of ulcerated plaques in the aortic arch in patients with stroke. N Engl J Med. 1992;326(4):221-5.

61. Tunick PA, Nayar AC, Goodkin GM, Mirchandani S, Francescone $\mathrm{S}$, Rosenzweig BP, et al. Effect of treatment on the incidence of stroke and other emboli in 519 patients with severe thoracic aortic plaque. Am J Cardiol. 2002;90(12):1320-5.

62. Dressler FA, Craig WR, Castello R, Labovitz AJ. Mobile aortic atheroma and systemic emboli: efficacy of anticoagulation and influence of plaque morphology on recurrent stroke. J Am Coll Cardiol. 1998;31(1):134-8. 
63. Amarenco P, Davis S, Jones EF, Cohen AA, Heiss WD, Kaste $\mathrm{M}$, et al. Clopidogrel plus aspirin versus warfarin in patients with stroke and aortic arch plaques. Stroke. 2014;45(5):1248-57.

64. Graus F, Rogers LR, Posner JB. Cerebrovascular complications in patients with cancer. Medicine (Baltimore). 1985;64(1):16-35.

65. Howlader N, Noone A, Krapcho M, Miller D, Bishop K, Altekruse S, et al. SEER Cancer Statistics Review, 1975-2013.: National Cancer Institute. Bethesda, MD; 2016.

66. Kneihsl M, Enzinger C, Wunsch G, Khalil M, Culea V, UrbanicPurkart T, et al. Poor short-term outcome in patients with ischaemic stroke and active cancer. J Neurol. 2016;263(1):150-6.

67. Navi BB, Iadecola C. Ischemic stroke in cancer patients: a review of an underappreciated pathology. Ann Neurol. 2018;83(5):873-83.

68. Nouh AM, Staff I, Finelli PF. Three Territory Sign: An MRI marker of malignancy-related ischemic stroke (Trousseau syndrome). Neurol Clin Pract. 2019;9(2):124-8. This study provides evidence associating the appearance of three territory involvement on DWI-MRI with malignancy-related stroke.

69. Dardiotis E, Aloizou AM, Markoula S, Siokas V, Tsarouhas K, Tzanakakis G, et al. Cancer-associated stroke: pathophysiology, detection and management (Review). Int J Oncol. 2019;54(3):779-96.

70. Guo YJ, Chang MH, Chen PL, Lee YS, Chang YC, Liao YC. Predictive value of plasma (D)-dimer levels for cancer-related stroke: a 3-year retrospective study. J Stroke Cerebrovasc Dis. 2014;23(4):e249-54.

71. Farge D, Frere C, Connors JM, Ay C, Khorana AA, Munoz A, et al. 2019 international clinical practice guidelines for the treatment and prophylaxis of venous thromboembolism in patients with cancer. Lancet Oncol. 2019;20(10):e566-81.

72. Key NS, Khorana AA, Kuderer NM, Bohlke K, Lee AYY, Arcelus JI, et al. Venous thromboembolism prophylaxis and treatment in patients with cancer: ASCO clinical practice guideline update. J Clin Oncol. 2020;38(5):496-520.

73. Dong E, Du H, Gardner L. An interactive web-based dashboard to track COVID-19 in real time. Lancet Infect Dis. 2020;20(5):533-4.

74.•• Siow I, Lee KS, Zhang JJY, Saffari SE, Ng A, Young B. Stroke as a neurological complication of COVID-19: a systematic review and meta-analysis of incidence, outcomes and predictors. J Stroke Cerebrovasc Dis. 2021;30(3):105549. Review and meta-analysis of 30 international studies discussing the incidence, predictors and mortality of COVID 19-related ischemic stroke.

75. Boehme AK, Luna J, Kulick ER, Kamel H, Elkind MSV. Influenzalike illness as a trigger for ischemic stroke. Ann Clin Transl Neurol. 2018;5(4):456-63.

76. Elkind MS, Tondella ML, Feikin DR, Fields BS, Homma S, Di Tullio MR. Seropositivity to Chlamydia pneumoniae is associated with risk of first ischemic stroke. Stroke. 2006;37(3):790-5.

77. Ohland J, Warren-Gash C, Blackburn R, Mølbak K, ValentinerBranth P, Nielsen J, Emborg HD. Acute myocardial infarctions and stroke triggered by laboratory-confirmed respiratory infections in Denmark, 2010 to 2016. Eurosurveillance. $2020 \mathrm{Apr}$ 30;25(17):1900199.

78. Smeeth L, Thomas SL, Hall AJ, Hubbard R, Farrington P, Vallance P. Risk of myocardial infarction and stroke after acute infection or vaccination. N Engl J Med. 2004;351(25):2611-8.

79. Merkler AE, Parikh NS, Mir S, Gupta A, Kamel H, Lin E, et al. Risk of ischemic stroke in patients with coronavirus disease 2019 (COVID-19) vs patients with influenza. JAMA Neurol. 2020. This analysis from a single academic medical center during the height of the corona virus pandemic provides evidence that the risk of stroke after COVID-19 is higher than it was after influenza during prior years.

80. Allegra A, Innao V, Allegra AG, Musolino C. Coagulopathy and thromboembolic events in patients with SARS-CoV-2 infection: pathogenesis and management strategies. Ann Hematol. 2020;99(9):1953-65.

81. Yamakawa M, Kuno T, Mikami T, Takagi H, Gronseth G. Clinical characteristics of stroke with COVID-19: a systematic review and meta-analysis. J Stroke Cerebrovasc Dis. 2020;29(12):105288.

82. Yaghi S, Ishida K, Torres J, Mac Grory B, Raz E, Humbert K, et al. SARS-CoV-2 and Stroke in a New York Healthcare System. Stroke. 2020;51(7):2002-11.

83. Ramos-Araque ME, Siegler JE, Ribo M, Requena M, Lopez C, de Lera M, et al. Stroke etiologies in patients with COVID-19: the SVIN COVID-19 multinational registry. BMC Neurol. 2021;21(1):43.

84. South K, McCulloch L, McColl BW, Elkind MS, Allan SM, Smith CJ. Preceding infection and risk of stroke: an old concept revived by the COVID-19 pandemic. Int J Stroke. 2020;15(7):722-32.

85. Lawler PR, Goligher EC, Berger JS, Neal MD, McVerry BJ, Nicolau JC, et al. Therapeutic anticoagulation with heparin in noncritically ill patients with Covid-19. N Engl J Med. 2021 Aug 4. Epub ahead of print.

86. Nouh A, Mehta T, Hussain M, Song X, Ollenschleger M. Clot composition of embolic strokes of undetermined source: a feasibility study. BMC Neurol. 2020;20(1):383. (This study provides preliminary evidence correlating red cell-to-platelet ratios with stroke etiology in endovascularly-retrieved intracranial clots.)

87. Falcione S, Kamtchum-Tatuene J, Sykes G, Jickling GC. RNA expression studies in stroke: what can they tell us about stroke mechanism? Curr Opin Neurol. 2020;33(1):24-9.

88. Dykstra-Aiello C, Sharp FR, Jickling GC, Hull H, Hamade F, Shroff N, et al. Alternative splicing of putative stroke/vascular risk factor genes expressed in blood following ischemic stroke is sexually dimorphic and cause-specific. Front Neurol. 2020;11:584695.

Publisher's Note Springer Nature remains neutral with regard to jurisdictional claims in published maps and institutional affiliations. 